\title{
El Clima en Texcoco
}

Vol. 1, No. 7. Julio 2019

www.grandmendmexico.mx/clima DOI: https://doi.org/10.35243/ect19.01

\section{REPORTE DE VARIABLES AMBIENTALES REGISTRADAS EN LA ESTACIÓN METEOROLÓGICA GRAND MEND MÉXICO DEL MES DE JULIO DEL 2019}

Hernández-Mendieta, Ernesto y Rubio-Granados, Catalina

Grand Mend México, S.A. de C.V. Netzahualcóyotl 214. Piso 3, Oficina 6-A. Col. Centro. 56100.

Texcoco, Estado de México. México. Tel. +52 595955 8379; E-mail: grandmend.mexico@gmail.com

Publicación en línea: Agosto 1, 2019

DOI: https://doi.org/10.35243/ect19.01.07b

ESTACIÓN METEOROLÓGICA GRAND MEND MÉXICO

$19^{\circ}$ 29' 17.62" N; 98 51' 57.28” O; Alt: 2298 msnm Inicio de Operaciones: Enero 4 del 2019

JULIO 2019

\begin{tabular}{|c|c|c|c|c|c|c|c|c|}
\hline & \multicolumn{3}{|c|}{ Temperatura $\left({ }^{\circ} \mathrm{C}\right)$} & & \multicolumn{2}{|c|}{ Vel. Viento $(\mathrm{km} / \mathrm{h})$} & & \\
\hline Dia & Media & Máx. & Min. & $\% \mathrm{HR}$ & Media & Máx. & Barómetro & Pres (mm) \\
\hline 1 & 16.43 & 21.80 & 12.10 & 76.98 & 4.60 & 29.00 & 1028.00 & 1.80 \\
\hline 2 & 16.42 & 22.20 & 11.40 & 75.90 & 4.43 & 29.00 & 1027.69 & 22.20 \\
\hline 3 & 16.73 & 22.30 & 11.70 & 76.74 & 2.96 & 20.90 & 1029.60 & 3.60 \\
\hline 4 & 17.80 & 24.90 & 12.20 & 73.76 & 5.23 & 37.00 & 1027.02 & 0.00 \\
\hline 5 & 18.34 & 26.70 & 11.80 & 65.70 & 5.42 & 41.80 & 1028.48 & 0.00 \\
\hline 6 & 17.28 & 24.90 & 11.20 & 71.94 & 4.89 & 43.50 & 1028.83 & 0.00 \\
\hline 7 & 17.05 & 25.10 & 11.30 & 72.90 & 3.36 & 33.80 & 1028.61 & 0.20 \\
\hline 8 & 16.47 & 25.30 & 11.60 & 72.75 & 4.87 & 41.80 & 1028.17 & 1.00 \\
\hline 9 & 16.86 & 25.70 & 9.80 & 71.77 & 5.08 & 40.20 & 1027.98 & 1.40 \\
\hline 10 & 16.81 & 23.10 & 13.40 & 82.33 & 3.74 & 30.60 & 1027.99 & 0.00 \\
\hline 11 & 16.86 & 21.90 & 13.70 & 80.47 & 3.77 & 38.60 & 1026.94 & 0.20 \\
\hline 12 & 16.54 & 22.10 & 13.20 & 82.85 & 3.01 & 20.90 & 1025.37 & 13.00 \\
\hline 13 & 17.27 & 24.10 & 14.30 & 81.88 & 3.08 & 27.40 & 1025.73 & 1.80 \\
\hline 14 & 16.71 & 24.20 & 11.90 & 82.72 & 2.74 & 33.80 & 1026.67 & 10.60 \\
\hline 15 & 18.02 & 26.40 & 12.20 & 78.38 & 2.89 & 29.00 & 1026.52 & 0.80 \\
\hline 16 & 18.15 & 26.10 & 14.00 & 71.21 & 5.05 & 46.70 & 1027.59 & 0.00 \\
\hline 17 & 16.35 & 20.80 & 11.60 & 74.91 & 2.49 & 22.50 & 1028.21 & 0.00 \\
\hline 18 & 16.52 & 23.90 & 12.20 & 75.03 & 3.12 & 27.40 & 1027.61 & 1.20 \\
\hline 19 & 16.67 & 23.30 & 12.50 & 80.37 & 3.42 & 27.40 & 1026.87 & 2.20 \\
\hline 20 & 16.98 & 24.30 & 11.40 & 75.90 & 3.31 & 24.10 & 1026.26 & 0.00 \\
\hline 21 & 16.41 & 23.20 & 12.00 & 75.26 & 6.04 & 40.20 & 1027.30 & 0.00 \\
\hline 22 & 16.53 & 23.90 & 10.60 & 73.17 & 4.82 & 30.60 & 1027.29 & 1.20 \\
\hline 23 & 16.35 & 21.90 & 11.20 & 78.67 & 2.75 & 27.40 & 1028.06 & 2.80 \\
\hline 24 & 14.93 & 21.20 & 12.90 & 86.74 & 2.99 & 24.10 & 1028.73 & 18.60 \\
\hline 25 & 14.89 & 19.50 & 12.10 & 86.40 & 3.09 & 25.70 & 1028.36 & 7.00 \\
\hline 26 & 15.44 & 20.70 & 12.40 & 86.72 & 2.95 & 25.70 & 1028.92 & 1.20 \\
\hline 27 & 16.35 & 23.50 & 12.00 & 81.83 & 3.40 & 33.80 & 1029.89 & 2.80 \\
\hline 28 & 15.84 & 24.20 & 10.30 & 78.15 & 3.29 & 30.60 & 1029.60 & 5.40 \\
\hline 29 & 15.90 & 21.10 & 10.70 & 77.46 & 3.24 & 25.70 & 1027.74 & 0.00 \\
\hline 30 & 16.78 & 23.90 & 10.50 & 71.61 & 3.93 & 33.80 & 1027.94 & 0.00 \\
\hline 31 & 16.69 & 23.90 & 10.90 & 75.07 & 5.12 & 33.80 & 1027.95 & 1.00 \\
\hline Media & 16.66 & 23.42 & 11.91 & 77.28 & 3.84 & 31.51 & 1027.80 & $100.00 *$ \\
\hline
\end{tabular}

*Valor Acumulado Mensual 
ESTACIÓN METEOROLÓGICA GRAND MEND MÉXICO

$19^{\circ} 29^{\prime} 17.62$ " N; $98^{\circ}$ 51' 57.28” O; Alt: 2298 msnm

Inicio de Operaciones: Enero 4 del 2019

JULIO 2019
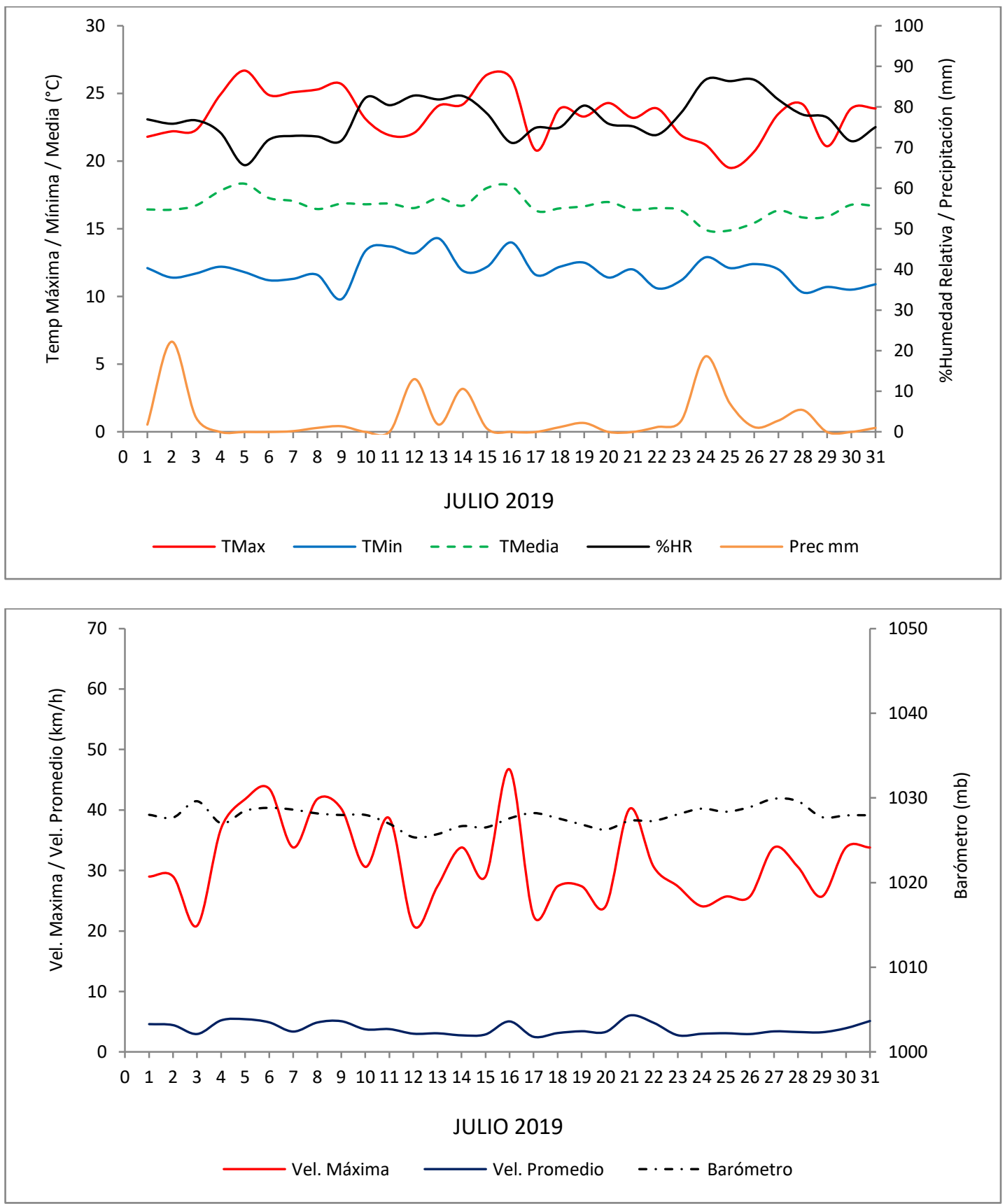